\title{
A Study on the Training of Localized Interpreters under Simulated Situations
}

\author{
Jianying Wang ${ }^{1, a}$, Heting Zhou ${ }^{2, b}$ \\ ${ }^{1}$ Shaoxing University Yuanpei College, Shaoxing, 312000, China \\ ${ }^{2}$ Zhejiang Industry Polytechnic College, Shaoxing, 312000, China \\ aemail: b.fair_1983@163.com \\ bemail: heting.zhou@163.com
}

Keywords: simulated situations; training of localized interpreters; undergraduate interpretation program

\begin{abstract}
With the Shaoxing interpretation market as an example, this article puts forward that undergraduate interpretation program of local colleges should be based on the needs of the local market and the actual situation of their students. To simulate situations of interpreting tasks, select materials reflecting features of the local regions, and adopt an occupational multiple dynamic evaluation mechanism is the only way to train a qualified localized interpreter.
\end{abstract}

\section{Introduction}

With the ever deepening of China's globalization, the demand for interpreters is expanding, and the training of interpreters has no time to waste. From 2006, the Ministry of Education has approved 196 universities of setting up Bachelor of Translation and Interpretation (BTI), and 158 universities of setting up Master of Translation and Interpretation (MTI). Meanwhile, domestic scholars have conducted in-depth discussion and research on interpreting theories and interpreting training methods, with some well-known colleges and universities exploring actively the training modes and methods of interpreting teaching. These studies are of great significance to the construction of interpretation theories and the studies of interpreting teaching. However, the practical researches on the training of primary and intermediate interpreters are quite limited, and the researches on the training of localized interpreters by local colleges and universities are still far from mature. In fact, local colleges and universities shoulder the responsibility of training front-line translators and interpreters, and a simple copy of training models of high-end interpreters is not feasible and practical. In 2012, in the Ninth National Conference on Interpretation with the theme of the Exploration of the Training Mode of Interpreters in the Era of Globalization, Professor Liu Heping pointed out that colleges and universities should cultivate localized interpreters to best serve local economy ${ }^{[1]}$. Bao Chuanyun also stressed in the Seminar of Training Interpreting Teachers in 2013 that interpretation teaching programs for undergraduates should take into consideration the actual situation of students, the orientation of school and the requirements of regional economy ${ }^{[2]}$.

Shaoxing, located in the south of Yangtze River Delta, is a world-famous textile trade center. The rapid development of foreign trades requires a large number of interpreters who can manage business communication and business negotiations. Shaoxing is also a historical and cultural city with a history of 2500 years and is well-known for its revers, yellow rice wine, calligraphy, bridges and celebrities. An all-round opening up of the city demands a large number of primary interpreters in the fields of foreign affairs, tourism, cultural exchanges, etc. This geographical feature requires colleges and universities in Shaoxing to undertake the task of cultivating professional interpreters which will boost the local economy. However, with graduates of Department of Foreign Languages of Shaoxing University Yuanpei College as an example, the employment researches of the resent three years (2013-2015) showed that the language capability, communication ability and interpretation skills of these students needs improving. This means that the existing mode of training interpreters requires a comprehensive reform, and a brand new mode of training localized 
interpreters by designing simulated situations needs to be constructed.

\section{Construction of Training Mode of Localized Interpreters Based on Simulated Situations}

The construction of training mode of localized interpreters based on simulated situations could be realized by adopting the following three steps: first, to simulate interpreting situations and urge students to do the interpretation in an effective way which will ensure a natural transition from simulated interpreting to real interpreting; second, to select interpreting materials reflecting geographical features of Shaoxing; third, to evaluate properly the learning process, and interpreting social practices of students with formative assessment by adopting occupational standards of interpretation.

\subsection{Design of interpreting tasks under Simulated Situations}

Many scholars pointed out that situational factors are of great significance in interpreting activities. Pöchhacker states that the process of interpreting...... is a kind of situational communication behavior in certain social activities ${ }^{[3]}$. Zwaan's researches show that the construction of situation model in translation process is an important part of acquisition of translation skills ${ }^{[4]}$. Kiraly also advocated that the translation teaching should be based on real translation projects ${ }^{[5]}$. Situations are factors that cannot be ignored in interpretation training. The design of simulated situations based on real interpreting tasks makes students be in a working environment of interpretation at any time. For example, in September, 2014, Shaoxing Municipal Bureau of Commerce sets up an activity named "Investment in Shaoxing" for investors in Shaoxing with an aim of giving them a better knowledge of the city. Against such a background, the teacher simulated this situation in classes of the interpreting program. In the preparing stage, the teacher helps students analyze the situation, including time, place, spokesman, the target audience, the purpose, the working mode and the scene of this interpretation task. Meanwhile, the teacher provides the students with the background knowledge of these investors, including their characteristics, their knowledge of Shaoxing and China and so on. In addition, students are required to memorize the expression of certain technical words and relevant information by surfing on the Internet and reading some bilingual texts. In the stage of interpretation, teacher tries to simulate the real scene of the conference of "Investment in Shaoxing" with the help of student guests and student audience, display the communication between the speaker and the presented investors and maintain an atmosphere of tension. The student interpreters, therefore, can fully experience and understand the situation, and convey the information fluently in an accurate manner by applying comprehensively interpretation skills and a variety of non-linguistic factors. After the simulation, the teacher organizes student guests and audience to assess the interpretation in terms of content-conveying and live performance. The teacher also encourages student interpreters to do self-assessment which will let them better understand the occupational norms and standards of interpreters, and help to accumulate interpreting experience. The construction of simulated interpreting situations is in accordance with the law of students' cognition and learning process, and gives the students constant chances to practice.

In addition, the interpretation projects under the cooperation between schools and enterprises also allow students to have access to the real interpretation tasks. Against the background of rapid development of Shaoxing's foreign trades and frequent foreign exchanges, Shaoxing University Yuanpei College has established long-term cooperative relations with Shaoxing Municipal Bureau of Commerce, Shaoxing Municipal Bureau of Culture, as well as a number of travel agencies, foreign trade companies, etc. Every year, under the guidance of the interpreting teachers, the students get many opportunities to participate some interpretation projects, such as being the volunteers of "World Choir Games" and "International Textile Trade Fair", and experience the liaison interpretation and other simple interpretation tasks. In the real working environment, students can constantly improve their psychological quality, cognitive ability and professionalism through observation, practice and reflection. The combination of simulating interpreting situations in class and experiencing interpretation tasks out of the class assists a natural transition from student 
interpreters to professional interpreters, effectively improving students' practical interpreting ability and quality of professionalism.

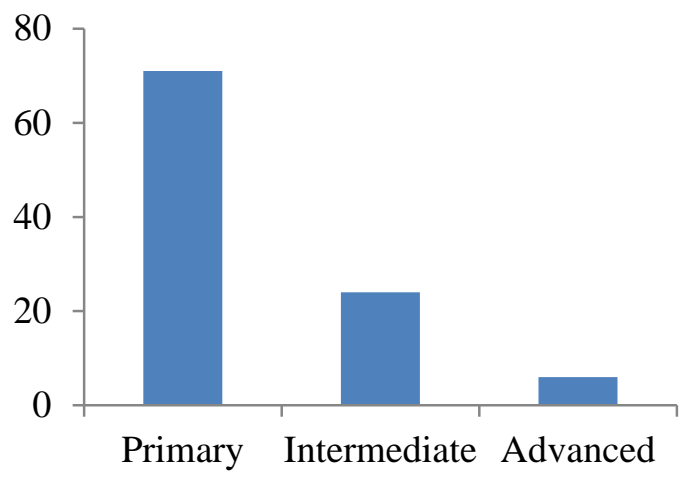

Fig.1 Hierarchical Distribution of Demand for Interpreters in Shaoxing

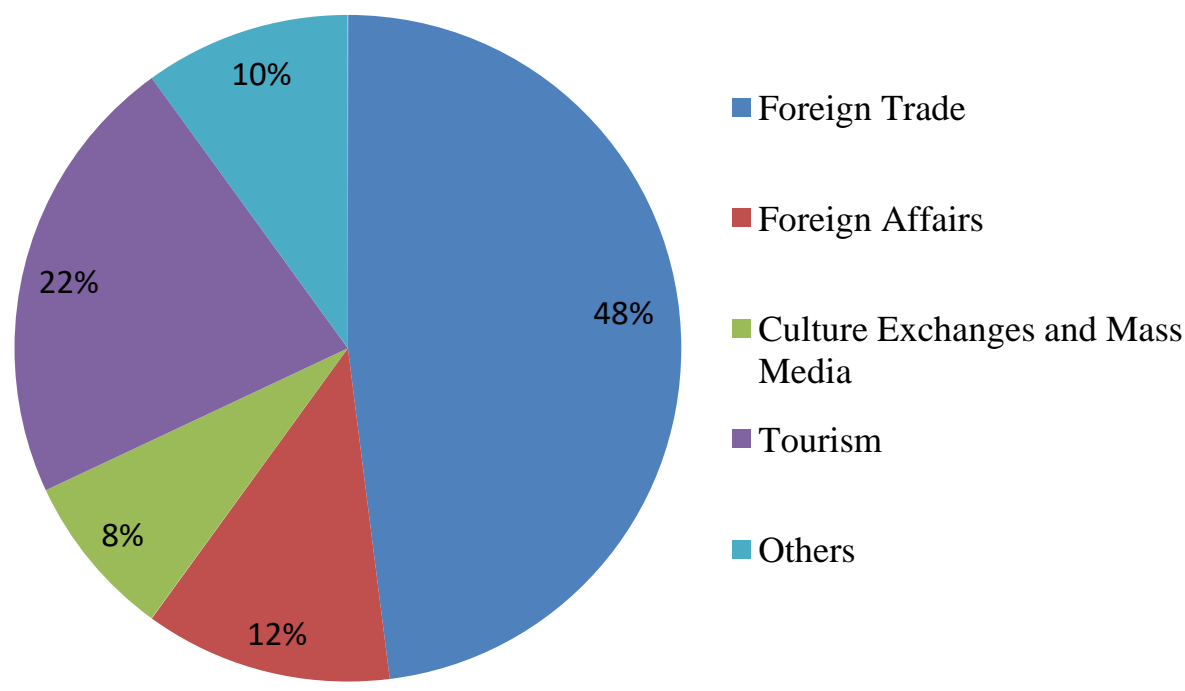

Fig.2 Types of Interpretation Applied in Shaoxing

\subsection{Selection of Interpreting Materials Reflecting Local Features}

Professor Bao Chuanyun stressed that "the textbooks of undergraduate translation programs should focus on flexibility and applicability of its language instead of the quantities of themes introduced, which aims to cultivate student's language competence and translation ability in proper scenes." ${ }^{[6]}$. According to a market survey (which involves a number of foreign institutions of the Shaoxing government, the departments of international exchanges of colleges and universities in Shaoxing and more than 100 foreign trade companies and travel agencies having frequent economic and trade exchanges abroad), Shaoxing needs a large number of primary interpreters and a considerable number of intermediate interpreters (Figure 1); interpreters with technical background, such as textile trade, foreign affairs, tourism are particularly favored (Figure 2). Therefore, in the undergraduate interpreting programs, teachers should not only train students' ability of listening comprehension,, note-taking, bilingual conversion, but emphasize the "localization" in selecting training materials. The interpretation teaching team of Shaoxing university Yuanpei College often collects authentic translation and interpretation materials and applies them in its interpretation programs, which include business negotiations of some textile foreign trade companies, the introduction of scenic spots in Shaoxing, and documents to be translated or interpreted in Foreign Affairs Office of Shaoxing and Shaoxing Municipal Bureau of Commerce. With these materials, teachers will help strengthen a specific interpretation skill, or the comprehensive mastery of interpretation skills. Here, the program of "Intermediate Interpretation” is to be taken as an example. 
The program, covering 32 periods of class, is divided into four major themes considering social and economic features of Shaoxing's development, namely, "Welcome to Shaoxing", "Travel around Shaoxing", "Invest in Shaoxing" and "Shaoxing-a Historical and Cultural Museum without Walls" (Table 1)

Table 1 Theme of "Intermediate Interpretation" and Respective Teaching Objectives

\begin{tabular}{|c|c|c|c|}
\hline Theme & $\begin{array}{l}\text { Interpreting skills + training } \\
\text { materials }\end{array}$ & Teaching Objectives & Class Period \\
\hline \multirow{2}{*}{$\begin{array}{l}\text { Welcome to } \\
\text { Shaoxing }\end{array}$} & $\begin{array}{l}\text { public speaking skills } \\
\text { +ceremonial speech delivered in } \\
\text { Keqiao International Textile } \\
\text { Fair }\end{array}$ & $\begin{array}{l}\text { To improve oral English } \\
\text { expression, communication } \\
\text { skills, psychological quality }\end{array}$ & $\begin{array}{l}4 \text { periods }+4 \\
\text { extracurricular } \\
\text { periods }\end{array}$ \\
\hline & $\begin{array}{l}\text { Listening comprehension+ } \\
\text { speeches delivered in opening } \\
\text { and closing ceremonies of } \\
\text { "World Choir Games" }\end{array}$ & $\begin{array}{l}\text { To improve the ability of } \\
\text { retelling and summarization }\end{array}$ & $\begin{array}{l}6 \text { periods }+6 \\
\text { extracurricular } \\
\text { periods }\end{array}$ \\
\hline $\begin{array}{l}\text { Travel around } \\
\text { Shaoxing }\end{array}$ & $\begin{array}{l}\text { interpreting ability +the Project } \\
\text { of "Tour around Shaoxing with } \\
\text { Our Chinese Textbooks" }\end{array}$ & De-verbalization & $\begin{array}{l}6 \text { periods }+6 \\
\text { extracurricular } \\
\text { periods }\end{array}$ \\
\hline $\begin{array}{l}\text { Shaoxing-a } \\
\text { Historical and } \\
\text { Cultural } \\
\text { Museum } \\
\text { without Walls }\end{array}$ & $\begin{array}{l}\text { Note-taking+ BBC’s “The Story } \\
\text { of China”(Shaoxing)/ Documents } \\
\text { of Shaoxing opera’s entry into the } \\
\text { Oceania }\end{array}$ & $\begin{array}{l}\text { To form an individualized } \\
\text { note system }\end{array}$ & $\begin{array}{l}6 \text { periods }+6 \\
\text { extracurricular } \\
\text { periods }\end{array}$ \\
\hline $\begin{array}{l}\text { Invest in } \\
\text { Shaoxing }\end{array}$ & $\begin{array}{l}\text { Bilingual conversion+ business } \\
\text { negotiations between textile } \\
\text { foreign trade companies }\end{array}$ & $\begin{array}{l}\text { To practice one’s ability of } \\
\text { liaison interpretation and } \\
\text { sight interpretation }\end{array}$ & $\begin{array}{l}6 \text { periods }+6 \\
\text { extracurricular } \\
\text { periods }\end{array}$ \\
\hline $\begin{array}{l}\text { Press } \\
\text { Conference }\end{array}$ & $\begin{array}{l}\text { Press conference interpretation + } \\
\text { Conference on National Network } \\
\text { Media, Shaoxing }\end{array}$ & $\begin{array}{l}\text { The comprehensive mastery } \\
\text { of interpreting skills, }\end{array}$ & $\begin{array}{l}4 \text { periods }+4 \\
\text { extracurricular } \\
\text { periods }\end{array}$ \\
\hline
\end{tabular}

In addition to the materials of real interpretation tasks (Table 1), teachers of interpreting programs of Shaoxing University Yuanpei College also select suitable audio and video materials from Internet like news programs, conference speeches, and interviews as the training materials. The selection of training materials should take into consideration not only the content, but also the types and degree of difficulty so as to ensure student's motivation of learning interpretation and maintain their interest. Meanwhile, teachers should always pay attention to students' feedback on interpreting practices, and make timely adjustment.

\subsection{Application of an Occupational Multiple Dynamic Evaluation Mechanism}

" Evaluation serves as an important part of translation teaching, which plays an important role in guiding, predicting, identifying, communicating, motivating, regulating and managing the whole teaching system " $[7]$. According to the market survey, employers today attach great importance to the professionalism of interpreters. Therefore, interpreting teachers should have a strong awareness of professionalism in evaluating students' interpreting performances with a series of operable standards, which emphasizes not only the comprehensiveness and accuracy of the content, the fluency of expressions, but also various factors including interpreters' voice, postures, etc. However, considering the reality of our students, it is difficult for them to meet all the professional standards in a short time. Therefore, teachers adjust the proportion of different criteria mentioned above in the whole evaluation system according to the development of students' interpreting ability at different stages. Such a dynamic assessment system not only highlights the key points of interpreting teaching at different stages, but helps students to overcome the fear of difficulty and thus gradually achieve the standards of a professional interpreter. With the program of Intermediate Interpretation as an example, the teacher divides the whole semester into five stages, each of which has its teaching emphasis:

The first stage: to enhance students' ability of logical analysis, and integration in listening comprehension. 
The second stage: to consolidate and improve students' comprehensive ability of information storage.

The third stage: to strengthen students' bilingual ability of thinking and conversion.

The fourth stage: to enhance students' awareness of professionalism.

The fifth stage: to improve the accuracy and fluency of information release.

The teacher designed four tests in one semester by taking into consideration the teaching objectives and the comprehensive level of interpreting skills.

Test one: to examine students' ability of listening comprehension (by retelling short passages after listening which accounts for $20 \%$ of the total of final examination).

Test two: to examine the ability of information integration and comprehensive expression (by summarizing short passages after listening, which accounts for $20 \%$ of the total of final examination).

Test three: to examine the ability of comprehensive expression of target language (by giving a detailed introduction of an appointed object with the assistance of multimedia in limited time, which accounts for $25 \%$ of the total of final examination)

Test four: to examine the comprehensive mastery of various interpreting skills (by simulating conference interpreting, which accounts for $35 \%$ of the total of final examination)

The teacher arranges 2 or 3 simulation exercises before each test to let the students fully aware the forms and difficulty of the test. At the same time, the teacher will evaluate individual performance with vision. That is to say, to appreciate student's achievements in a certain period of time and to encourage students to overcome the psychological fear in doing interpretation.

In addition to the phased tests set by teachers, the occupational multiple evaluation mechanism also emphasizes the diversity of content and methods of assessments. For instance, teachers will set autonomous learning tasks and cooperative learning tasks throughout the whole teaching process which includes preview before class, exploration and discussion in class and consolidation by practices after class. And the performance of all these tasks will be considered in making an assessment. Teachers will establish a social service portfolio for every student, such as to do volunteer works in "International Textile Fair in Keqiao, China", which records his/her social practices and social services concerning interpretation, and reward him/her extra scores in final grades. Moreover, the final evaluation fully integrates student's self-assessment, peer assessment, teacher's evaluation and student's feedback of the interpreting teaching. Therefore, teachers shall gradually become a guide, assistant, and promoter of interpreting learning.

\section{Student's Performance after the Reform}

The project of training localized interpreters based on simulated situations was carried out in the Department of Foreign languages in Shaoxing University Yuanpei College from March 2016 to July 2016, with 196 English majors as its subjects. And the final examination still adopts the previous forms with similar degree of difficulty. By the end of the semester, these students are required to conduct a questionnaire survey, and handed it over then and there. The findings are shown in the following tables:

Table 2. Students' Attitudes towards Traditional Teaching and Teaching based on Simulated Situations

\begin{tabular}{c|c|c|c|c|c|c}
\hline & \multicolumn{2}{|c|}{ Pros } & \multicolumn{2}{c}{ Neutral } & \multicolumn{2}{c}{ Cons } \\
\cline { 2 - 7 } & number & proportion & number & proportion & number & proportion \\
\hline Traditional Teaching & 56 & $30 \%$ & 49 & $26 \%$ & 82 & $44 \%$ \\
\hline $\begin{array}{c}\text { Teaching based on } \\
\text { Simulated Situations }\end{array}$ & 127 & $65 \%$ & 35 & $18 \%$ & 34 & $17 \%$ \\
\hline
\end{tabular}


Table 3. Scores of Final Examination of English Majors Grade 2012 and Grade 2013

\begin{tabular}{l|c|c|c|c|c|c}
\hline & Attendance number & A (\%) & B (\%) & C (\%) & D (\%) & Average \\
\hline $\begin{array}{l}\text { English Majors Grade } \\
\begin{array}{l}\text { 2012(Traditional } \\
\text { Teaching) }\end{array}\end{array}$ & 187 & $9 \%$ & $23 \%$ & $50 \%$ & $16 \%$ & 71.5 \\
\hline $\begin{array}{l}\text { English Majors Grade } \\
\begin{array}{l}\text { 2013(Teaching based on } \\
\text { Simulated Situations }\end{array}\end{array}$ & 196 & $15 \%$ & $27 \%$ & $39 \%$ & $17 \%$ & 76 \\
\hline
\end{tabular}

Table 4 Social Practices, Contests and Certificate Tests Concerning Interpretation among English Majors Grade 2012 and Grade 2013

\begin{tabular}{l|c|c|c|c|c}
\hline & \multicolumn{2}{|c|}{$\begin{array}{c}\text { Interpreting Social } \\
\text { Practices }\end{array}$} & \multicolumn{2}{|c|}{ Interpreting Contests } & \multicolumn{2}{c}{$\begin{array}{c}\text { Certificate Tests of } \\
\text { Qualified Interpreters }\end{array}$} \\
\cline { 2 - 6 } & Attendance number & $\begin{array}{c}\text { Attendance } \\
\text { number }\end{array}$ & $\begin{array}{c}\text { Number of } \\
\text { winners }\end{array}$ & $\begin{array}{c}\text { Attendance } \\
\text { number }\end{array}$ & Pass rate \\
\hline $\begin{array}{l}\text { English Majors Grade } \\
\begin{array}{l}\text { 2012(Traditional } \\
\text { Teaching) }\end{array}\end{array}$ & 34 & 4 & 1 & 60 & $78 \%$ \\
\hline $\begin{array}{l}\text { English Majors Grade } \\
\begin{array}{l}\text { 2013(Teaching based on } \\
\text { Simulated Situations) }\end{array}\end{array}$ & 60 & 7 & 3 & 114 & $88 \%$ \\
\hline
\end{tabular}

These findings fully indicate that the teaching based on simulated interpreting situations not only gives students enough motivation and interest in learning interpretation, but also improves their interpreting ability to some extent. However, during the process of implementation of the training model, there are still many aspects to be improved. For instance, in designing a real interpretation task, teachers shall help students overcome anxiety and prevent a state of being at a loss by providing them access to the resources needed which will assist the preparation before interpretation. Moreover, teachers shall play a role of supervision, guidance and coordination in the system of simulated interpreting situations, and make sure each student get the opportunity to practice and gain progress.

\section{Conclusions}

Proceeding from the professionalism of interpreters, the training mode of localized interpreters based on simulated situations combines together the social content, students' cognitive path and communicative effects of interpreting teaching, and provides a reliable theoretical basis. With continuous improvement and exploration by fully embodying the simulation and practicability in interpreting teaching, a large number of qualified interpreters will be cultivated to better serve the social and economic development the region.

\section{Acknowledgement}

In this paper, the research was sponsored by the Teaching Reform of Shaoxing's Institutions of Higher Education.

\section{Reference}

[1] Liu Heping, Xu Ming. The Exploration of the Training Mode of Interpreters in the Era of Globalization: a Review of the Ninth National Conference on Interpretation [J]. Chinese Translators Journal, 2012 (5): 53-59.

[2] Bao Chuanyun. Lectures on the Training of Teachers of MTI and BTI in the Summer of 2013.2013.

[3] Pöchhacker, Franz. From Operation to Action: Process Orientation in Interpreting Studies [J]. 
Meta, 50 (2), 2005.

[4] Zwaan, Rolf A. \& Gabriel A. Radvansky. Situation Models in Language Comprehension and Memory [J]. Psychological Bulletin, 123 (2), 1998.

[5] Kiraly, Donald. Project-based Learning: A Case for Situated Translation [J]. Meta, 50 (4), 2005.

[6] Bao Chuanyun. A Study on the Teaching of Undergraduate Interpreting Programs [J]. Foreign Language Education, 2008 (0): 1-7.

[7] Wang Shuhuai, Wang Weiping. Translation Teaching Assessment: a Developmental Model [J]. Journal of PLA University of Foreign Languages, 2010 (5): 76-78. 